\title{
O processo civilizatório da infância pelo corpo: um pouco do que a História nos conta
}

The civilization of children's civilization of childhood: a little bit of History

El proceso civilizatorio de la infancia por el cuerpo: un poco de que la Historia nos cuenta

Nair Correia Salgado de Azevedo Universidade do Oeste Paulista (Brasil) https://orcid.org/0000-0003-2914-3278

http://lattes.cnpq.br/0283353697981017 nairazevedo@hotmail.com

José Milton de Lima

Universidade Estadual Paulista Júlio de Mesquita Filho (Brasil)

https://orcid.org/0000-0001-5519-2618

http://lattes.cnpq.br/7758444123838079

milton.lima@unesp.br

\section{Resumo}

A questão do cerceamento dos corpos infantis nas escolas, por meio da disciplinarização, levanos a refletir sobre quando e por que tais práticas pedagógicas baseadas nessa visão se tornaram ações dentro da "normalidade" e perduraram ao longo de décadas de escola pública no Brasil. Esse artigo parte do pressuposto de que muitas ações repressoras do lúdico, infelizmente, bastante comuns em muitos contextos escolares e que resultam numa disciplinarização corporal, são consequências de imposições históricas às crianças. É possível inferir que muitos eventos históricos contribuíram para que tais visões ainda prevaleçam no contexto escolar, o que consequentemente resulta em uma educação engessada e que tende a não valorizar as culturas lúdicas infantis presentes dentro das escolas. Importa pensarmos que, independente de imposições disciplinares corporais, nossas crianças continuam a produzir cultura - o que nos parece ser digno de novas discussões, é como podemos mudar concepções e práticas historicamentes adquiridas a respeito dessa temática.

Palavras-chave: Infância. Disciplinarização do corpo. História da Educação. 


\begin{abstract}
The question of curtailing children's bodies in schools through disciplinarization leads us to reflect on when and why such pedagogical practices based on this vision became actions within "normality" over decades of public schooling in Brazil. This article is based on the assumption that many repressive actions of the playful, unfortunately very common in many school contexts and that result in a corporal discipline, are results of historical impositions to the children. It is possible to infer that many historical events contributed to the fact that such visions still prevail in the school context, which consequently results in an education that is plastered and that tends not to value the Children's Children's Cultures present within the schools. It is important to think that, regardless of corporal disciplinary impositions, our children continue to produce culture - what seems to us worthy of new discussions, is how we can change our historically acquired view on this subject.
\end{abstract}

Keywords: Childhood. Disciplinarization of the body. History of Education.

\title{
Resumen
}

La cuestión del cercenamiento de los cuerpos infantiles en las escuelas por medio de la disciplinarización nos lleva a reflexionar sobre cuándo y por qué tales prácticas pedagógicas basadas en esa visión se convirtieron en acciones dentro de la "normalidad" a lo largo de décadas de escuela pública en Brasil. Este artículo parte del supuesto de que muchas acciones represivas del lúdico, desgraciadamente bastante comunes en muchos contextos escolares y que resultan en una disciplinarización corporal, son resultados de imposiciones históricas a los niños. Es posible inferir que muchos eventos históricos han contribuido a que tales visiones aún prevalezcan en el contexto escolar, lo que consecuentemente resulta en una Educación encolada y que tiende a no valorar las Culturas Lúdicas Infantiles presentes dentro de las escuelas. Es importante pensar que, independientemente de las imposiciones disciplinarias corporales, nuestros niños continúan produciendo cultura - lo que nos parece ser digno de nuevas discusiones, es cómo podemos cambiar nuestra visión históricamente adquirida acerca de esta temática.

Palabras clave: Infancia. Disciplinarización del cuerpo. Historia de la Educación. 
Dona Cleópatra, que tomava conta do portão, já estava de cara feíssima, que pra ela, chegar atrasado na escola era pior que bater na mãe...

- Já pra dentro, crianças. Joguem fora o chiclé, onde é que já se viu? Ó Tábata, você está cansada de saber que não pode entrar de fita vermelha na cabeça. $\mathrm{E}$ nada de risadinhas no corredor que atrapalha as outras classes, nada disso, nada daquilo, não pode, não pode! As crianças correram para a classe, bateram na porta e entraram, muito ressabiadas... A professora também já estava na lição do "Não Pode".

- Não pode escrever no caderno com a caneta vermelha. Esta é só pros títulos. E não pode sentar de lado que é pra não atrapalhar os vizinhos. E não pode olhar pro lado, nem pra trás, e nem dar risadinhas, nem pode ficar mostrando figurinhas, esta porcaria de álbum, exploração de multinacional, vamos acabar com isso, e vamos acabar com essas conversas de programas de TV, é por isso que o Brasil não vai pra frente, crianças, não verão país como esse.

(Ruth Rocha - A menina que aprendeu a voar) ${ }^{1}$

\section{Introdução}

A citação introdutória deste trabalho, apesar de se tratar de uma história fictícia, pode perfeitamente ser confundida com a vida real de muitas escolas hoje - não é difícil percebermos cenas parecidas com a descrita pela "menina que aprendeu a voar", e dizemos isso baseandonos em experiências próprias de nosso cotidiano como docentes e pesquisadores em muitas escolas. O furto das práticas lúdicas, a imobilidade, a disciplinarização por meio do corpo, em muitos contextos escolares, tornam-se mais do que ações costumeiras - eles tornam-se um hábito ou algo "dentro da normalidade".

A questão central, nesse caso, parece tentar compreender como, quando e por que tais práticas pedagógicas que reprimem a ludicidade nos contextos escolares ganharam força e precisamos refletir como isso foi construído ao longo de décadas de escola pública no Brasil. Nossa discussão parte do pressuposto de que muitas ações repressoras do lúdico, infelizmente, bastante comuns em muitas instituições escolares, são resultados de imposições históricas às crianças.

Na literatura mundial, tem sido crescente o interesse pela história da infância. Há trabalhos muito reconhecidos como os de Kohan (2003), Gagnebin (2013), Erikson (S/D), Agamben (2014) e o clássico "História social da criança e da família" de Philippe Ariès (1978). Já Kuhlmann Júnior (1998) relaciona a evolução do olhar humano sobre a infância com a emancipação da mulher e as mudanças sociais ocorridas, especialmente, a partir do século XIX.

Além disso, outra instituição teve um importante papel para o reconhecimento e a mudança de paradigmas com relação à infância: a escola. A escolarização infantil implicou para o desenvolvimento de várias ações sociais, como a criação de leis e estatutos, o surgimento de ideologias políticas e pedagógicas, além de ocasionar uma transformação dos núcleos

\footnotetext{
${ }^{1}$ ROCHA, R. A menina que aprendeu a voar. São Paulo: Moderna, 2012, 32 p.
} 
familiares. Entraremos em mais detalhes sobre esses aspectos nesse estudo mais adiante (ARIÈS, 1978; KUHLMANN JÚNIOR, 1998).

Pretendemos, nesse trabalho, discutir sobre a influência que alguns eventos históricos tiveram a respeito da visão que ainda temos de que a criança, no contexto escolar, aprende melhor por meio da disciplinarização do corpo. Outras discussões também serão relevantes, como a história da infância brasileira, a criança como o futuro da nação (especialmente a partir da década de 1890) e o perfil no qual essa criança seria moldada pela recém-reformulada escola pública paulista no contexto da I República (1890 - 1930).

\section{História da infância brasileira: primeiras aproximações}

Apesar de o trabalho de Ariès (1978) receber várias críticas, como por exemplo, o fato de sua análise iconográfica basear-se apenas em perceber a infância burguesa a partir do século XII, no contexto europeu e que tais interpretações não garantem que a infância tenha sido da forma como ele expõe, é possível inferir que a criança não teve voz ativa na sociedade mundial durante muito tempo. A infância, considerada na cronologia das "idades da vida" como a primeira idade do homem, era chamada pelo termo enfant que significa "não falante". A ideia de infância estava diretamente ligada à subordinação e só se saía dela quando se deixava de depender exclusivamente dos adultos para muitas coisas.

Segundo Ariès (1978) as "idades da vida" não correspondiam apenas a idades biológicas, mas também eram diretamente relacionadas às funções sociais: idade dos brinquedos (em que as crianças brincavam); idade da escola (em que os meninos aprendiam a ler e as meninas a fiar); idade do amor, esporte e corte (em que moças e rapazes participavam de festas e passeios); idade da guerra (em que os meninos aprendiam a manusear armas e andar a cavalo); e, finalmente, a idade sedentária (em que os homens da lei, da ciência e do estudo se tornavam velhos sábios e estudiosos).

Apenas por volta do século XIII é que as imagens de crianças começaram a ser expostas por meio de temas religiosos, como o menino Jesus, alguns santos e anjos. A partir do século XV, novas representações da infância surgiram como as ocorridas em efígies funerárias, por exemplo. E nesse caso, uma curiosidade: a maior parte das crianças mortas era representada não em seu próprio túmulo ou no túmulo de seus pais e familiares, mas sim no túmulo de seus professores (ARIÈS, 1978).

$\mathrm{O}$ sentimento daquela época nem de longe se assemelha aos sentimentos atuais. A opinião comum era de que não se deveria reconhecer nas crianças "nem movimento na alma, nem forma reconhecível no corpo" (ARIÈS, 1978, p. 57). As crianças eram tão insignificantes que não se temia nem que elas pudessem voltar após a morte para importunar os vivos!

Aos adultos, cabia-lhes até mesmo a função de "não se apegar" a nenhuma criança que nascia sob o seu teto. Ribeiro (1997) nos lembra de que, nesse caso, a criança era desprezada ou tratada como adulto em miniatura.

Até o século XVII, com efeito, o amor aos filhos não era coisa óbvia: basta lembrar o renascentista Montaigne, que diz ter perdido "duas ou três crianças" em tenra idade. Um pai assim poderia nem mesmo recordar quantos filhos teve; e notemos que se trata, não de natimortos, mas de crianças que viveram um, dois ou três anos. (RIBEIRO, 1997, p. 102).

Ribeiro (1997) ainda relata que na Idade Média, o poder era delegado ao governante, ou seja, ao superior da família patriarcal. Ao pai cabia a obrigação de proteger os inferiores crianças e mulheres eram vistas como carentes, necessitados de um tutor e incapazes de resolver seus problemas por si. 
Entre muitas questões que são importantes para esse estudo, outra que merece ser comentada é com relação às atividades lúdicas. Partindo da iconografia do historiador Van Marle, Ariés (1978) conclui que no século XVII e XVIII o divertimento dos adultos eram os mesmos das crianças. Vários quadros holandeses mostram essa interação retratando brincadeiras como a cabra-cega, jogos e danças circulares, por exemplo, com a participação de pessoas de todas as faixas etárias. As festas sazonais também eram ilustradas e percebe-se que tanto as crianças quanto os jovens desempenhavam papel importante nas realizações dessas. Os jogos e o lazer representavam, naquela época, muito mais que uma simples diversão: tratava-se de uma oportunidade que a sociedade tinha para estreitar laços coletivos e até realizar uniões.

Porém, já no século XV, começava a aparecer os primeiros sinais de que a educação escolar seguiria uma linha mais disciplinadora e menos lúdica. Idealizada pela igreja e com conotações morais, muitas das primeiras escolas que surgiram na Europa consideravam os jogos como atividades incontroláveis. O medo de causar tumulto e de tirar o foco da educação moral proibiu, em muitos momentos, a prática de atividades físicas no ambiente escolar (ARIÉS, 1978).

Muitas atividades de diversão eram restritas a alguns momentos após as tarefas consideradas "importantes", como as atividades intelectuais, por exemplo. Havia quem defendesse que a prática de atividades físicas era comparada aos trabalhos manuais e de esforço, vistos por muitas sociedades da época como trabalho pesado, realizado pela classe pobre e/ou escrava, sendo, portanto, oposta aos trabalhos intelectuais. "Os jogos só vem depois das tarefas, e mesmo assim sob reservas!" (ARIÉS, 1978, p. 111), dizia a bula do Cardeal de Amboise de Montagu, em 1501.

Apenas a partir do século XVII é que o jogo deixa de ser visto como "nocivo" por algumas instituições educacionais. Um dos primeiros grupos a ter essa visão foram os Jesuítas que, sob a influência dos humanistas do Renascimento, perceberam as possibilidades educativas dos jogos nas práticas pedagógicas. Os padres optaram então por não reprimir o jogo, mas sim inclúi-lo oficialmente em seus programas de ensino (ARIÈS, 1978).

Por meio dessa difusão positiva do jogo pelos jesuítas, apareceu então um sentimento novo na área educacional: a adoção dos jogos como um mal menor necessário à educação das crianças. No "Traité de l'éducation des enfants" de 1722 (ARIÉS, 1978) lemos que o corpo precisa se agitar enquanto cresce e no fim do século XVIII a justificativa para a inclusão dos jogos de exercício nas escolas era patriótica, pois eles auxiliavam a preparar os jovens para a guerra. "Compreenderam-se então os benefícios que a Educação Física podia trazer à instrução militar" (ARIÉS, 1978, p, 113).

No Brasil, os Jesuítas também mantinham um vínculo missionário especialmente a partir do século XVI, época em que nosso país era colônia de Portugal e, portanto, uma terra com muito a ser explorada. Por aqui, além da conversão dos "gentios" aos fundamentos cristãos, o ensino das crianças brasileiras era uma das principais preocupações dos padres da "Companhia de Jesus" desde os primórdios de sua missão na América portuguesa. (CHAMBOULEYRON, 2010).

A "Companhia de Jesus", ordem essencialmente missionária e criada no início do século XVI, se transformou em uma "ordem docente" no Brasil, o que já ocorria pela Europa. Portanto, além da conversão das pessoas ao catolicismo, os padres dessa ordem também se preocupavam com as crianças e enxergavam na educação uma oportunidade dos preceitos da igreja chegarem a seus pais.

Neste contexto, a evangelização das crianças tornara-se uma forma de viabilizar uma difícil conversão, já que, como escrevia em continuação à mesma carta, nos meninos se poderia esperar muito fruto, uma vez que pouco contradiziam a lei cristã. Com os adultos cada vez mais arredios, toda a atenção se voltava aos filhos destes, explicava o então irmão José de Anchieta aos padres e irmãos de Coimbra, em finais de abril de 1557 (CHAMBOULEYRON, 2010, p. 52). 
Portanto, as crianças brasileiras serviriam também para a construção de alianças, principalmente entre padres cristãos e índios. Os meninos, além de constituírem uma nova cristandade, seriam ensinados na doutrina cristã com bons costumes, aprendendo a falar, ler e escrever em português e isso afetaria de alguma maneira os seus pais.

A educação proporcionada pelos jesuítas, porém, não era vista pela sociedade em geral como algo importante para a colônia naquela época. A instrução para as atividades de produção em si não requeriam grandes esforços intelectuais, quer do ponto de vista de sua administração, quer seja do ponto de vista da mão de obra (ROMANELLI, 2010). Portanto, o ensino era marginalizado e visto como algo sem utilidade prática necessária para o avanço da produção rudimentar, considerados muito importantes naqueles tempos.

Os Jesuítas permaneceram ainda por um bom tempo nesse processo de "docência religiosa", pois eles tinham também outro objetivo: o recrutamento de fiéis servidores do cristianismo (ROMANELLI, 2010). A educação não era oferecida apenas aos "curumins", mas também aos filhos dos colonos promovendo assim uma manutenção da fé. Foi pensando justamente no recrutamento de jovens sacerdotes que se fundaram os primeiros colégios onde se passaram a ensinar as ciências humanas, das letras e da teologia. Eram desses colégios que saíam grande parte de novos sacerdotes da Ordem.

Mesmo com a expulsão dos Jesuítas em 1759, o modelo implantado por eles ainda perdurou durante um tempo. Entre a saída dos religiosos da esfera educacional até as primeiras providências a serem tomadas sobre como seguiria a educação no Brasil a partir daquele momento, somaram-se mais de treze anos. Houve uma ruptura da estrutura de ensino e várias modificações, entre elas a implantação de disciplinas isoladas e a introdução de leigos no ensino que passava a ser administrado a partir dali pelo Estado. Mas, segundo Romanelli (2010), apesar de várias tentativas não houve grandes mudanças no sistema de ensino, pois o mesmo continuou mais tarde com objetivos religiosos e literários, utilizando-se dos mesmos métodos pedagógicos jesuíticos e com forte apelo à disciplina e à autoridade.

É propício lembrar nesse momento que, a Educação no Brasil entre os séculos XVIII e meados do século XIX eram para alguns meninos. Nem todas as meninas eram autorizadas a frequentar as escolas para se alfabetizarem e os meninos que entravam nessas escolas assim faziam com idades já avançadas, geralmente a partir de dez anos. Enquanto que por volta dos anos de 1843-1844, na Alemanha e em todo o continente europeu, surgiam os primeiros jardins de infância fundados por Fröebel, o Brasil sequer pensava em instituições nesse formato e, ainda, para crianças pequenas (SANTANA, 2011).

Segundo Del Priore (2010), o primeiro jardim de infância criado no Brasil surgiu em 1896, em São Paulo, foi inspirado na concepção de Pestalozzi e, embora público, a elite da época foi favorecida ao ter prioridade nas matrículas. O fato é que até meados do século XIX, muitas pessoas ainda enxergavam o trabalho infantil como sendo melhor que a escola, ou seja, o trabalho, além de complementar a renda da família, evitava que a criança ficasse ociosa.

Isso era fruto de uma educação que chegou tardiamente em nosso país se comparados a outros países ocidentais em que o capitalismo se instalou no alvorecer da Idade Média. O Brasil, país pobre, com resquícios e hábitos do sistema colonial antigo, com uma industrialização tardia, não encontrou espaço para que novas questões, entre elas as relacionadas ao ensino público, florescessem. "Sem a presença de um sistema econômico que exigisse a adequação física e mental dos indivíduos a esta nova realidade, não foram implementados os instrumentos que permitiriam a adaptação a este novo cenário" (DEL PRIORE, 2010, p. 10).

Veremos, a partir desse momento, como a infância brasileira era vista a partir da década de 1890. Queremos desde já mencionar que, assim como Lajolo (1997), pensamos que os estudos históricos acerca da infância são um conjunto de ciências que expressa as várias impressões sobre as crianças, realizadas por pessoas "de fora" e demonstrando crenças sobre a infância que, em muitos momentos, podem ser destituídas de valores e contradições. "Em 
conjunto, artes e ciências vão favorecendo que a infância seja o que dizem o que ela é... e, simultaneamente, vão se tornando o campo a partir do qual se negociam novos conceitos e novos modos de ser da infância" (LAJOLO, 1997, p. 232).

Nossa intenção, entretanto, é refletir sobre alguns acontecimentos históricos a partir da década de 1890 e que contribuíram para que a existênica, ainda hoje, em nossas escolas de alguns tipos de privações da/para a infância, como a disciplinarização do corpo, o furto do lúdico, os métodos tradicionais e a resistência ao novo que, em muitos momentos, ainda presenciamos no contexto escolar atual.

\section{O contexto progressista brasileiro e as ações para a infância: a criança como "herdeira" da República}

A abolição oficial da escravatura em 1888 representava, em parte, algumas mudanças no cenário brasileiro. Dizemos "em parte", pois muitos hábitos, principalmente aqueles relacionados à ideologia e ao predomínio de costumes da classe dominante (entendemos como "classe dominante" nesse contexto, o homem branco, burguês e europeizado, não necessariamente europeu) permaneceram (e, por que não dizer, permanece) enraizados durante muito tempo na sociedade brasileira.

Primeiramente precisamos entender que a "Abolição da escravatura" não significou a liberdade plena dos negros no Brasil naquela época. Como nos lembra Del Priore (2010), após a Abolição muitas das crianças e adolescentes que viviam nas senzalas permaneceram por lá devido à falta de condições de se manter de forma autônoma - continuaram a trabalhar nas fazendas atuando em trabalhos pesados ou como empregados domésticos. A outra opção seria se aventurar pelas primeiras cidades coloniais, o que terminaria quase sempre numa vida de mendicância e miséria.

No século XVIII, terminada a euforia da mineração, crianças vindas de lares mantidos por mulheres livres e forras, perambulavam pelas ruas vivendo de expedientes muitas vezes escusos - os nossos atuais "bicos" - e de esmolas. As primeiras estatísticas criminais elaboradas em 1900 já revelavam que esses filhos da rua, então chamados de "pivettes", eram responsáveis por furtos, "gatunagem", vadiagem e ferimentos, tendo na malícia e na esperteza as principais armas de sua sobrevivência. Hoje, quando interrogados pelo serviço social do Estado, dizem com suas palavras o que já sabemos desde o início do século: a rua é um meio de vida! (DEL PRIORE, 2010, p. 13).

Pouco mais de um ano, após a promulgação da Lei Áurea, o Brasil do final do século XIX vivia também outro momento histórico: a passagem de Império (disfarçado de governo regido por fazendeiros escravocratas, como preferem alguns) para a República. Dom Pedro II, imperador de nosso país na época e responsável pela formalização do regime, serviu de árbitro político entre os que eram resistentes à ideia republicana e os grupos que defendiam a liberdade de expressão, sobretudo no contexto político. Dom Pedro II não foi considerado um absolutista, nem um político ousado como seu pai, Dom Pedro I, e embora com boas intenções, seu governo deixou como herança uma tradição de valorização das instituições e uma centralização em grupos políticos elitistas que se mantiveram limitados e fechados por muito tempo (CARVALHO, 1997).

O Brasil vivia, então, um momento de muitas discussões sobre como buscar a evolução para um país que, de colônia, queria se tornar um sinônimo de desenvolvimento para o mundo. Segundo Kuhlmann Júnior (1998), o conceito de civilização influenciou as principais ideias em todo o mundo nesse momento. Entende-se por conceito de "civilização" a crença no progresso pela ciência e a mobilização entre várias nações para se adaptarem ao novo processo de 
produção. "Os países fizeram inventários de suas potencialidades e realizações, e as histórias sobre vários aspectos da vida social, escritas nesse período, anunciavam o trilhar da civilização para o progresso" (KUHLMANN JÚNIOR, 1998, p. 27).

Nesse contexto, um verdadeiro espírito de nacionalismo envolveu vários setores sociais num movimento que percorreu a Europa, os Estados Unidos, chegando à América Latina e, consequentemente, ao Brasil. Em meio às várias correntes na época, como as transformações políticas, econômicas sociais e capitalistas, surgia também a preocupação com uma figura até então invisível: a criança, que deixa de ser objeto de interesse único da família e da igreja, e passa a ser alvo também das ações do Estado (RIZZINNI, 2011).

Nesse contexto, a criança representava o "futuro da nação", pois se fosse educada a tempo, seria muito útil a médio e longo prazo para os ideais republicanos. Conforme Rizzini (2011), esse contexto exigia a elaboração de um plano de prevenção, recuperação e repressão, pois a criança era considerada um ser que precisava ser vigiado, educado, moldado e, se fosse o caso, recuperado, visto que a criança ameaçadora era assim vista por ser criada solta e de forma indisciplinada, conduzidas pelas "escolas do crime", como as ruas e as casas de detenções.

Não era difícil de observar no Brasil do final do século XIX e início do século XX, que muitos problemas sociais já afetavam nosso país demonstrado por um cotidiano bastante excludente, o que afetava diretamente as crianças brasileiras. Tal fato é percebido principalmente pelos estrangeiros que passavam ou vinham morar no Brasil naquela época, como podemos perceber em algumas das cartas de Ina Von Binzer (2011):

Rio de Janeiro, 24 de dezembro de 1881. De noite.

[...] Volto a admirar aqui a resistência dos nervos dos nativos; apesar do barulho ensurdecedor, vivem todos na rua ou mais ou menos na rua. Se, segundo o princípio sustentado por um famoso professor de Berlim, todo homem culto procura viver recolhido em sua casa, chegaremos à conclusão que, em matéria de cultura, nos encontramos aqui em condições idênticas às de Abraão em relação aos justos, em Sodoma. Os pretos desocupados não se encontram senão na porta da rua fumando e cuspindo; as crianças rolam na rua de manhã à noite; o pequeno negociante e até mesmo o melhor comerciante das ruas distintas postam-se na porta quando não há freguesia, tagarelando com quem passa; quando o sol permite, cada sacada e cada janela fica ocupada por basbaques ociosos. (BINZER, 2011).

Leite (1997) em seu estudo realizado sobre análises de cartas de viajantes pelo Brasil durante século XIX nos retrata muitas curiosidades sobre os costumes dos brasileiros nesse período. A autora nos alerta para o fato de evitarmos julgamentos precipitados, visto que se trata do olhar de quem escreve tais cartas, mas é possível perceber que, para muitos estrangeiros, o brasileiro não era bem visto devido a muitos de seus costumes, como o fato das crianças dos senhores e as crianças negras brincarem juntas e soltas pelas fazendas, das mães brancas entregarem seus bebês para que as pretas das fazendas amamentassem e cuidassem delas por muito mais tempo, de que quando, enfim, houve a abolição dos escravos, surgiram muitas pessoas vagando pelas ruas, de que a família brasileira tinha uma maneira totalmente diferente de criar seus filhos e, também, o fato de as crianças brasileiras iniciarem-se na vida adulta por meio do sexo e do vício precocemente.

Vemos em fragmentos de duas das cartas, publicadas pelo estudo de Leite (1997), que muitas das crianças eram consideradas "adultas" para muitas coisas: 
No Brasil não existem crianças no sentido inglês. A menor menina usa colares e pulseiras e meninos de 8 anos fumam cigarros. Encontrei um bando de meninos voltando da escola, uma tarde. Um pequeno, de aparentemente sete anos tirou do bolso um maço de cigarros e ofereceu a um de cada vez. Ninguém demonstrou qualquer desaprovação de um menino tão pequeno estar fumando. A linguagem desses meninos é terrível, embora eu precise admitir que, como os cocheiros de Londres, não percebem que estão usando expressões chulas (EDGECUMBE, 1886, apud LEITE, 1997, p. 39).

Cenas como essas, no novato Brasil republicano, incomodava muita gente. Foi durante essa época que a criança começou a ser vista como delinquente, mas também como um ser moldável: era necessário, sobretudo, que o Estado intervisse e acolhesse esses seres "moralmente" abandonados.

Segundo Kuhlmann Júnior (1998) a intencionalidade educativa começa a ter protagonismo a partir das discussões que buscavam colaborar para que o Brasil se tornasse "civilizado" - nesse momento, a infância passa a ser considerada, especialmente a partir de 1870, pelas esferas jurídicas, sanitárias e educacionais. Na esfera jurídica, a preocupação era com essa criança delinquente, de família pobre, que precisava ser controlada e regenerada. Na esfera sanitária a discussão era sobre como poderia se controlar a distribuição social na perspectiva da melhoria da raça do brasileiro e do cultivo do nacionalismo e, por fim, na esfera educacional, como a escola poderia contribuir em todas essas ações por meio da disciplina moral, intelectual e corporal.

Para Rizzinni (2011), educar a criança pobre significava moldá-la para a submissão. Havia, nesse período, uma preocupação em educar o povo, pois as esferas econômicas mundiais naquele contexto exigiam outro tipo de preparo: a capacitação para um mercado de trabalho totalmente diferente daquele no qual o Brasil estava acostumado desde sua colonização. Era preciso repensar uma educação que contemplasse os ideais capitalistas que estavam surgindo, aos poucos, nos horizontes brasileiros. Porém, a preocupação da elite letrada também era de promover uma educação para civilizar sem, no entanto, abrir mão do controle e da vigilância que, antes se aplicavam às senzalas e agora se aplicariam a outros meios de trabalho. Vale a pena destacar que os pobres eram vistos como uma ameaça à elite burguesa e eles (os pobres) jamais poderiam desconfiar que juntos pudessem causar rebeliões, protestos e reivindicações sociais que poderiam ser de extrema relevância para uma equidade social no Brasil. A ideia era modernizar, mas manter o status quo.

Portanto, a infância passou a ser vista como um membro da ação civilizadora nesse período, digna de preocupações e planejamentos futuros. As mudanças comportamentais a respeito das crianças, como por exemplo, os atos de violência física e moral, considerados comuns em determinadas épocas, passa a ser visto como reprovação, pois a criança era o futuro na nação, um "vir a ser" que construiria nosso país.

Foi nesse contexto, segundo Kuhlmann Júnior (2010), que circulou muitas ideias novas sobre a infância por meio de encontros, simpósios e congressos internacionais nos quais a elite intelectual brasileira tentava se introduzir. Inicialmente, essa participação brasileira era marcada por relações pessoais ocorridas em viagens e também pelas primeiras edições e traduções de publicações. Mais tarde, no último terço do século XIX, essas relações se ampliam pelas associações e congressos de nível nacional e internacional, que difundiam tais propostas institucionais e pedagógicas.

$\mathrm{Na}$ América Latina, as discussões começaram a se destacar a partir do século XX. Seguindo os exemplos dos congressos internacionais da época, foi realizado o $1^{\circ}$ Congresso Americano da Criança em Buenos Aires, em 1916. O segundo ocorreu em 1919 em Montevidéu e o terceiro, realizado no Rio de Janeiro em 1922 durante o Centenário da 
Independência organizado em conjunto com o $1^{\circ}$ Congresso Brasileiro de Proteção à Infância. Conforme Kuhlmann Júnior (2010), o período entre 1870 e 1920 foi de pensar propostas e iniciativas que pudessem começar os debates sobre as relações com a infância e a organização educacional, que passa a ter maior visibilidade com a formalização pelo Estado das instituições e associações que contribuiriam com essa formação da criança brasileira em diferentes esferas, como instâncias administrativas, políticas, educacionais, científicas, culturais, entre outras.

Nessa mesma época, a obrigatoriedade da presença das crianças nas escolas começava a entrar em discussão no cenário educacional brasileiro. Na Europa, segundo Marcílio (2010), isso já acontecia desde o século XVII. Era preciso, porém, que o Brasil resolvesse outro problema, de cunho muito maior que o da obrigatoriedade em si das crianças nas escolas: era preciso que as próprias escolas brasileiras realmente existissem. No fim da época imperial, num momento histórico não muito distante do contexto que acabamos de descrever, as aulas de primeiras letras funcionavam em ambientes totalmente precários, acanhados, sem iluminação e ventilação, além de serem impróprios e sujos. Vejamos em Marcilio (2010) uma descrição de uma escola de São Paulo em 1864, que pode ser considerada válida para todas as demais escolas brasileiras na época do Império:

A "escola" funcionava na mesma casa em que morava o mestre-escola. Os professores de primeiras letras eram todos de classes pobres e só podiam alugar casas baratas, situadas nas áreas mais precárias e afastadas dos centros mais povoados das cidades e vilas. Muitas eram de pau a pique, cobertas de sapé e não raras vezes de chão de terra, acanhadas, sem luz suficiente e sem ventilação (MARCILIO, 2010, p. 48).

Ainda segundo Marcilio (2010), as escolas não possuíam materiais para a aprendizagem da leitura e da escrita, não contavam com livros, com mobílias para que as crianças se sentassem, nem com quadro negro e havia crianças de várias idades na mesma turma. Essa era a situação das escolas paulistas na década de 1870 quando o Império já demonstrava sinais de decadência.

Além disso, Marcílio (2010) ainda nos lembra de que outros fatores, como a distância a ser percorrida pelas crianças de casa até à escola (algumas andavam aproximadamente duas horas para chegar até as unidades escolares), a necessidade de se trabalhar para ajudar em casa e outras formas de distrações, como as mesas de jogos (essa atividade nesse período era uma prática bastante disseminada e popular por aqui), contribuíam para que as crianças e adolescentes abandonassem os estudos. Dessa forma, a taxa de evasão era bastante alta e a frequência era de número bastante inferior em relação ao número de alunos matriculados.

O Brasil estava cheio de problemas sociais e houve, nesse momento de alvorecer das ideias republicanas, uma união entre médicos, juristas e religiosos para que se pensasse como deveria ser a educação e a assistência às crianças brasileiras. No quesito "revolução educacional", veremos mais adiante que o Estado de São Paulo saiu na frente e foi o pioneiro no Brasil no sentido de repensar a educação para a modernidade, tornando-se modelo para os demais Estados do Brasil especialmente no período da I República, que vai de 1889 à década de 1930.

Antes, porém, de discutirmos como se deu esse processo revolucionário, como o currículo foi pensado e como a organização das instituições educacionais paulistas foram estabelecidos, pensamos ser relevante nesse momento realizar uma reflexão sobre a ideologia que esteve por trás de toda estrutura adotada por São Paulo e, principalmente, qual foi o papel da educação dos corpos infantis nesse processo histórico. 


\section{O processo civilizatório pela infância: disciplinarização por meio dos corpos infantis no ambiente escolar}

Já mencionamos anteriormente que várias instituições passaram a se preocupar com a infância no Brasil, especialmente no período da I República (1889 - 1930). Entre todas elas, a escola ocupou um papel protagonista nesse processo, porém isso não significou, a partir dali, uma verdadeira institucionalização da escola para as massas. Romanelli (2010) nos lembra de que, o que ocorreu desde a colonização das terras americanas foi um verdadeiro transplante cultural - a transferência de hábitos, costumes, ideias, formas de atividades comerciais e econômicas, tudo conforme a organização social e política do colonizador. Não foi diferente com a Educação.

Nesse caso, a transferência intelectual da classe social dominante acabou por nortear a implantação dos primeiros sistemas educacionais brasileiros. Nesse contexto da I República, a imposição e preservação de modelos importados educacionais priorizou o acesso à escola apenas para algumas crianças de classe social mais abastada. A escola era, então, uma instituição que priorizava uma pequena parcela da população (ROMANELLI, 2010).

Durante todo o Império a educação popular esteve abandonada. Com as ideias republicanas, vieram enfim as discussões sobre a necessidade de se ter escola para todos, pelo menos na teoria. Ocorre que com a Constituição da República em 1891, o sistema federativo descentralizou o ensino, como nos explica Romanelli (2010), o que resultou na seguinte divisão: o governo federal tomaria conta do ensino superior em todo o país; aos demais Estados brasileiros ficou a incumbência de criar e controlar com total autonomia o ensino primário e profissional que resultaram, na época, nas escolas normais para as moças e nas técnicas para os rapazes.

Essa organização favoreceu ao que Romanelli (2010) denomina de "dualidade de ensino", pois o governo federal se preocuparia com a escola para a classe dominante, enquanto os Estados se preocupariam com as escolas para o povo. Isso apenas formalizou o que já vinha acontecendo na época do Império, ou seja, não houve mudanças significativas no sistema de ensino brasileiro.

Levando em conta, portanto, as ideias elitistas da época, que foram formadas segundo padrões escravocratas com origens no período colonial, a implantação do "novo" sistema educacional brasileiro nesse período não teve mudanças substanciais. Colocando o ensino técnico e primário à mercê de cada Estado, obviamente o investimento educacional foi diferente em vários pontos de nosso país, visto que alguns Estados como São Paulo e Minas Gerais, por exemplo, tinham situação política e até econômica considerada privilegiada se comparados a muitos Estados do nordeste. Vemos, então, a educação e a cultura tomar mais impulso em algumas regiões, sobretudo em São Paulo e nos demais Estados da região sudeste do Brasil (ROMANELLI, 2010).

Adepto de ideias europeias, pois o Brasil acreditava que para ser civilizado precisaria tentar se equiparar à Europa, pensou-se novamente em importar tais ideias ocorrendo mais uma vez, como diria Romanelli (2010), um transplante cultural. No caso da escola brasileira, uma das ideias centrais tratava das formas de disciplinarização no contexto escolar que se dava, entre outras maneiras, por meio da conduta corporal.

Segundo Gomes-da-Silva (2012) é pelo corpo que se investe/investiu em estratégias civilizadoras e capitalistas. O corpo brasileiro é construto e construtor cultural de sentido e de significação. A educação do corpo brasileiro teve na ginástica um de seus primeiros modelos de conduta corporal, o que o autor define como "conduta corporal burguesa".

Conduta corporal, no sentido civilizador, porque entendemos ser ela um dos elementos que objetivam educar/civilizar o homem, desde a infância, modificando sua personalidade, ou prevenindo transgressões do comportamento socialmente aceitável, mediante uma pedagogia do gesto (GOMES-DA-SILVA, 2012, p. 13). 
O autor justifica o uso do termo "conduta motora ou corporal burguesa", não porque é típica do burguês, mas porque fazia parte dos objetivos burgueses substituir os padrões de vida do Brasil no início do século XX, buscando uma nova forma de organizar a economia de nosso país e realizar, ao mesmo tempo, um reordenamento social, e isso incluía reorganizar a conduta motora do corpo brasileiro, a fim de que ele pudesse atender a novos padrões de hábitos que fossem ao encontro do novo mundo automatizado (GOMES-DA-SILVA, 2012).

A conduta corporal burguesa tinha o objetivo de modelar o comportamento e gestos do indivíduo desde criança e teve sua primeira sistematização pedagógica denominada "Ginástica" no período das revoluções francesa, americana e industrial. Tal conduta foi incorporada como comportamentos civilizáveis e foi muito aceito na comunidade burguesa, portanto, denominada por Gomes-da-Silva (2012) de conduta "corporal burguesa".

A Ginástica, denominada mais tarde de Educação Física, era diretamente ligada à educação do corpo que era entendido como um ser humano, constituído de duas partes distintas e autônomas: o corpo e a mente. A Educação Física se tornou, então, a disciplina escolar que objetivava "educar o corpo" brasileiro que era deseducado, indelicado, rude, grosseiro, e cabia então à Educação Física na escola tornar esse mesmo corpo um corpo ágil, forte e esteticamente belo (GOMES-DA-SILVA, 2012).

O resultado, segundo os objetivos da educação burguesa, era um só: criar indivíduos civilizadamente bem-comportados e subordinados aos padrões que a sociedade dominante da época impunha. A educação burguesa não buscava, porém, apenas a educação do corpo pelos exercícios físicos, mas também objetivava a educação para o trabalho. Com a universalização do ensino, a Ginástica teve um importante papel na adaptação do trabalhador ao novo ritmo de vida e às novas tecnologias das fábricas. Nesse momento foi importante também pensar numa Ginástica que envolvesse as crianças e as mulheres, pois, segundo Gomes-da-Silva (2012), esses dois grupos estavam subordinados ao processo civilizador: a exploração do trabalho infantil e feminino estava entre os interesses estratégicos de aumento da produção e dos lucros.

Era grande a vontade de fazer com que o Brasil de tornasse um país culto, tentando se igualar aos patamares europeus, sobretudo no final do século XIX e início do século XX. O que se fazia na Europa era implantado em nosso país e para Gomes-da-Silva (2012), nesse contexto, priorizou-se uma conduta motora sistematizada, biomecanizada, que nada tinha a ver, como explicaremos mais adiante, com o corpo dos brasileiros.

A disciplinarização do corpo também é comentada por Foucault (1987): as escolas foram pensadas com a organização de um espaço seriado, com pessoas andando em filas, com o tempo organizado e determinado por um sinal. A obediência a uma única pessoa, o controle da atividade, e o ritmo coletivo pré-definido também são outras caraterísticas de docilização do corpo existentes até hoje em muitas instituições escolares.

Para Foucault (1987), trata-se de trabalhar o corpo detalhadamente, de exercer uma espécie de coerção sem folga para mantê-lo sempre no nível mecânico, impondo-lhes uma relação de docilidade-utilidade, o que podemos chamar de disciplina.

A disciplina fabrica corpos omissos e exercitados, corpos "dóceis". A disciplina aumenta as forças do corpo (em termos econômicos de utilidade) e diminui essas forças (em termos políticos de obediência). Em uma palavra: ela dissocia o poder do corpo; faz dele por um lado uma "aptidão", uma "capacidade" que ela procura aumentar; e inverte por outro lado a energia, a potência que poderia resultar disso, e faz dela uma relação de sujeição estrita (FOUCAULT, 1987, p. 127). 
Segundo Foucault (1987), nenhuma instituição realiza tão bem essa tarefa de disciplinar os corpos quanto a escola. Nelas, "as atividades são cerceadas o mais possível por ordens a que se tem que responder imediatamente" (FOUCAULT, 1987, p. 137) e o tempo medido e pago deve ser ininterrupto e anular tudo o que pode contribuir para qualquer distração que prejudique a produção.

Segundo Carvalho (1997), a escola brasileira se deixou levar nesse momento pelos novos ritmos da sociedade técnica e do maquinismo. Tratava-se de ritmos que prescreviam intervenções disciplinares pedagógicas. $\mathrm{O}$ ajustamento dos homens às novas condições de vida e aos novos valores exigia a padronização dos comportamentos e ações. Nesse caso, a adaptação do corpo infantil seria eficaz para o futuro do Brasil. "Disciplinar não é mais prevenir ou corrigir. É moldar. É contar com a plasticidade da natureza infantil, com sua adaptabilidade, com sua capacidade natural de ajustamento a fins postos pela sociedade" (CARVALHO, 1997, p. 308).

Todavia, como se dava, na prática, as ações para que ocorresse essa adaptação do corpo infantil ao novo ritmo, ditado pela sociedade e pelo contexto escolar? Se, as escolas brasileiras eram cheias de problemas e a autonomia dos Estados para a elaboração da educação técnica e primária provocou um distanciamento muito grande dos sistemas de ensino brasileiros entre si, como foi possível disciplinar os corpos infantis para esse "novo" Brasil? Como foi possível transformar a escola nessa máquina de ajustamento do "futuro da nação"?

Saindo recentemente de um regime escravocrata, o Brasil da década de 1890 demonstrava uma espécie de euforia com relação aos novos ideais que surgiam: a possibilidade de desenvolvimento econômico, político, social e educacional eram os temas que mais impulsionavam essa empolgação. Veremos a partir de agora, como esses ideais se consolidaram na Educação pública paulista também por meio da disciplinarização do corpo.

\section{A escola paulista da I República: para quem? Para que?}

Vimos até aqui que as escolas paulistas do final do século XIX funcionavam de forma muito precárias. Havia muitos problemas a serem solucionados e quando o governo decidiu delegar a organização do sistema de ensino técnico e primário para os Estados, São Paulo foi um dos primeiros a se mobilizar para que essa estruturação ocorresse, devido à euforia dos novos ideais e a vontade de se modernizar perante o país e o mundo.

É preciso, porém, lembrar que em momento anterior a então província do Rio de Janeiro, mais precisamente a capital fluminense, era o local que estava mais próximo do tão almejado "estereótipo europeu" de civilização (RIZZINNI, 2011), devido à presença da corte portuguesa desde o início do século XIX.

O colégio Dom Pedro II, fundado em 1837, oferecia à elite carioca, embora se denominasse público, um estudo já seriado com a introdução de disciplinas como a música e a ginástica, por exemplo. O colégio era conhecido por possuir uma estrutura moderna para a época se comparado a outros, e o aluno saía formado em Letras, podendo ingressar em qualquer curso de ensino superior do país. Era, porém, pensado nos moldes imperiais, com objetivo de instruir os filhos da corte para que esses, futuramente, pudessem ingressar em algum ensino superior sem precisar se ausentar do Brasil para estudar na Europa (GÓIS JÚNIOR; BATISTA, 2010).

Também nessa mesma época, a partir de 1835, a província de São Paulo começava a dar os primeiros passos em direção à estruturação de uma Escola Normal que objetivava a formação de professores para atuar na educação primária. Essa estruturação, entretanto, foi lenta e gradual - em 1846 a assembleia paulista aprovou sua criação; em 1847 foi fundada a seção feminina (a seção masculina funcionou de 1846 até 1866); foi fechada em 1866, reaberta em 1875 já no prédio anexo à faculdade de Direito do Largo São Francisco e fechada novamente em 1878. Por todos esses motivos, é possível concluir que a educação paulista sentia dificuldade em consolidar seu sistema de ensino na época do Império (GÓIS JÚNIOR; BATISTA, 2010). 
Já na década de 1880, com o surgimento dos ventos de mudanças republicanas, a Escola Normal é reaberta. Com influência extremamente positivista, havia um clima de debate em vários setores que deveriam contribuir, naquele momento, para a educação das crianças paulistas: a legislação se manifestaria por meio dos juristas, a religião (mais precisamente o catolicismo) e o assistencialismo pelo serviço social e filantropia, os médicos pelo higienismo e eugenia e até os engenheiros por meio da arquitetura própria educacional (KUHLMANN JÚNIOR, 1998; MONARCHA, 1997).

Com relação à arquitetura escolar, São Paulo também se destacou como pioneiro e solucionou um problema da época muito relevante para que se ocorresse um possível avanço na qualidade do ensino: a construção de edifícios escolares, pensados nos moldes contemporâneos da época. A então "Escola Normal da Praça", como era popularmente conhecida em sua inauguração em 2 de agosto de 1894, causou uma verdadeira revolução arquitetônica educacional no Brasil (MONARCHA, 1997).

A nova configuração de construção educacional, pensada por republicanos paulistas, contemplava, pelo menos na teoria, as crianças paulistas em geral: desde os recém-chegados imigrantes, até a criança paulista negra, branca, mulata, mestiça, enfim, a "herdeira" da república. A "Escola Normal da Praça" tornou-se rapidamente o padrão a ser adotado na construção de novos grupos escolares em todo o país (MONARCHA, 1997).

Durante a década de 1890 foi organizado o ensino normal e primário, depois procederam a organização do ensino secundário, o Jardim de Infância e a cúpula do Ensino Politécnico paulista (MONARCHA, 1997), que foi realizada por Antônio Caetano de Campos, conhecida mais tarde como "Reforma Geral da Instrução Pública de São Paulo".

Segundo Góis Junior e Batista (2010), Antônio Caetano de Campos era médico e foi indicado ao cargo de Diretor da Escola Normal de São Paulo por Rangel Pestana, ativista do movimento republicano que, naquele momento, ocupava um dos cargos do governo provisório do Estado de São Paulo. Além de exercer a medicina, Caetano de Campos também era docente no Colégio Pestana (pertencente à família de Rangel Pestana), local onde se conheceram, e era simpatizante dos mesmos ideais pedagógicos considerados mais adequados pelo movimento republicano, entre eles a influência pedagógica baseada em Pestallozzi e Fröebel, e pelo modelo norte-americano educacional, baseado em princípios protestantes.

Caetano de Campos tinha um ideário biológico sobre a realidade que se casava com convicções liberais, o que era considerado por muitos, bastante coerente com esse contexto do final do século XIX. A reforma curricular da Escola Normal, assim como sua organização pela introdução de atividades práticas e utilitárias como, por exemplo, a Ginástica, se tornou o modelo republicano a ser seguido em todo o Brasil (GÓIS JUNIOR; BATISTA, 2010).

A disciplina de "Ginástica" e "Exercícios Militares" foi introduzida nas escolas primárias paulistas nessa reforma de 1890 e significava que a nova Escola Normal tinha um currículo moderno. Isso não indicava, porém, que essas disciplinas fossem realidade na maioria das escolas públicas de São Paulo, pois as aulas de Ginástica sofreram muitas dificuldades para serem efetivamente implantadas. Umas delas, era a falta de professores formados e, quando tais profissionais estavam presentes, mesmo tendo status e tratamento de professor, seu salário era mais baixo que os dos demais docentes. "Embora a Escola compreendesse a importância na formação do alunado, isto não se refletia na valorização do profissional” (GÓIS JÚNIOR; BATISTA, 2010, p. 81).

$\mathrm{O}$ fato que podemos dizer, que oficialmente, é a partir desse momento que ocorre a introdução da prática de atividades físicas no contexto escolar, visando à formação do ser humano, mais especificamente, à formação do futuro republicano de nosso país. No início da Escola Normal, as aulas aconteciam duas vezes por semana para os normalistas das seções masculina e feminina. Havia uma diferença em que, na seção feminina, não havia os "Exercícios Militares" que eram substituídos pela seção de "Prendas e Exercícios Escolares". Nas escolas primárias, a "Gymnástica" ocorria na seção masculina, nas séries equivalentes hoje do $1^{\circ}$ ao $5^{\circ}$ ano. Na seção feminina, as 
atividades eram realizadas três vezes por semana em todos os anos, com exceção do $1^{\circ}$ ano, que tinha aulas duas vezes por semana (GÓIS JÚNIOR; BATISTA, 2010).

Os argumentos para que as aulas de "Gymnástica" fossem introduzidas nos currículos escolares paulistas eram baseados na busca de uma educação integral, usando de teses que se sustentavam na visão do corpo como uma máquina que deveria ser cuidada e a típica ideia de mente sã em um corpo são (GÓIS JÚNIOR; BATISTA, 2010).

Para Carvalho (1997) os "novos" discursos que ostentavam a infância como o principal objeto de intervenção disciplinar era totalmente coerente com os discursos a respeito da intervenção por meio do corpo. A autora destaca que, já em 1914, ocorreu a mais ambiciosa implantação de práticas educativas tidas naquele momento como científicas: trata-se da instalação do Laboratório de Pedagogia Experimental, no gabinete de Psicologia e Antropologia Pedagógica, que funcionava num anexo da Escola Normal Secundária de São Paulo. O objetivo dessa nova instituição era se aperfeiçoar no "estudo científico" da infância, usando técnicas estrangeiras.

Para isso, foi convidado o Diretor da Escola Normal de Módena, na Itália, Ugo Pizzoli, para que se encarregasse da organização dos cursos de formação para os professores de todo o Estado de São Paulo. Entre as primeiras novidades que chama nossa atenção, é a criação de uma "Carteira Biográfica Escolar", que foi utilizada em todo o Estado paulista. Essa carteira deveria ser assinada pelo diretor da unidade de ensino, pelos professores de cada série e pelo médico escolar; conteria dados do aluno nos últimos cinco anos, como fotos anuais, observações antropológicas e fisiopsicológicas, além de anotações de dados anamnéticos da família, a compleição física, o tipo racial, traços morais, marcas de hereditariedade e índices de normalidade, anormalidade ou degenerecência. Com o cruzamento de todas essas informações é que se traçava o caráter específico do aluno (CARVALHO, 1997).

A intenção era de perceber, por exames físicos e clínicos, a personalidade normal e anormal das crianças e, ainda, discriminar aquelas que se enquadravam nos patamares físicos normal, anormal e ou degeneradas. No caso, os avaliados como normais, poderiam frequentar a escola normalmente, sem nenhum problema, enquanto que os anormais necessitariam de uma melhor especificação, distinguindo o tipo de anomalia que poderiam ser profundas ou simples e, nesses casos, eram facultados de frequentar a escola. Já os degenerados, deveriam ser totalmente excluídos das escolas dos normais, seja qual fosse seu caráter degenerativo (CARVALHO, 1997).

Era uma forma que a "Pedagogia Científica" procurou para justificar as desigualdades sociais e de tentar explicar o progresso e o atraso dos povos pelas marcas existentes em seus corpos que observados, medidos, classificados e corrigidos, se enquadravam em estereótipos determinados pela natureza e não, segundo tal avaliação, pela sociedade em si (CARVALHO, 1997).

Outros ideais também corroboraram para a questão da infância como principal objeto de intervenção pedagógica. O movimento dos kindergartens (Jardins da Infância) divulgado por Fröebel na Europa proclamava o papel protagonista da mulher na educação da infância as mulheres eram chamadas a transcender seu papel materno, doméstico e privado para o contexto pedagógico e público. Família e escola seriam complementares na educação das crianças e não mais dicotômicas nesse processo (KUHLMANN JÚNIOR, 1998).

O primeiro Jardim de Infância público paulista foi o "Jardim de Infância Caetano de Campos", um anexo da Escola Normal, inaugurado em 18 de maio de 1896. Era um prédio novo, com quatro salas grandes e um salão central que tinha, nas paredes, retratos de Froebel, Pestalozzi e Rousseau. Durante muito tempo, segundo Kuhlmann Júnior (1998), teve como clientela a elite paulistana, que tinha supostos privilégios e era favorecida nas matrículas.

A programação das atividades demonstrava uma preocupação com o controle e a vigilância das crianças, facilmente percebido pela própria divisão de horários: eram quatro horas de atendimento com previsão de vinte momentos diferentes de até quinze minutos cada. Aos sábados, as aulas tinham um horário mais livre, com exercícios orais de linguagem, jogos, cantos e passeios. De acordo com o "Guia das Jardineiras", o tempo recomendado para cada atividade era de 20 a 30 
minutos, os jogos deveriam ser realizados sentados e alternados com os jogos de ação (aqueles em que as crianças imitariam o voo dos pássaros, a natação, o ato de semear e lavrar a terra etc.), com a ginástica e com os exercícios vocais (KUHLMANN JÚNIOR, 1998).

Conforme Kuhlmann Júnior (1998) havia cinco modalidades de atividades desenvolvidas com as crianças durante a rotina: as atividades cotidianas (os rituais), as de linguagem, as atividades físicas, os dons e as atividades expressivas. As atividades de cada modalidade eram assim distribuídas: as atividades cotidianas eram consideradas rituais, pois ocorria todos os dias, como a entrada com canto e saudações, o repouso, o recreio, a refeição, os pensamentos, os cantos de despedida e a saída. As filas também eram consideradas as formações mais adequadas para o deslocamento das crianças; as atividades de linguagem eram aquelas ocorridas pelas narrativas e conversações, como os jogos de sons, a silabação, os diálogos, etc.; as atividades físicas estavam centradas em atividades como o recreio, os passeios e excursões, a ginástica, a marcha, os jogos cantados, os jogos organizados e os brinquedos. Também a ginástica, difundido por Fröebel como um trabalho integrado entre corpo e espírito, deviam ser exercícios regulamentados, progressivos do simples ao complexo, compreendido entre posições, extensões, passos, marchas, saltos e não deveria estar dissociada dos jogos e brincadeiras.

Já com relação aos brinquedos e jogos organizados, o primeiro termo se referia às brincadeiras de roda, de movimento e de imitações geralmente acompanhados de marchas cantadas, enquanto que o segundo são as atividades que propiciam o contato com a natureza e com outras pessoas por meio de exercícios físicos expressivos motores; os dons eram atividades que favorecia a educação dos sentidos de forma a desenvolver a expressão dos instintos infantis; e, por último, as atividades expressivas, eram as atividades de artes em geral, como as de desenho, pintura, música, reconhecimento de cores, etc. (KHULMANN JÚNIOR, 1998).

Kuhlmann Júnior (1998) também ressalta que as atividades nas escolas primárias eram realizadas com gestos e ações ritualizadas. A chegada e a saída da escola com músicas, em filas, os gestos dos educadores, as formações corporais, a repetição, entre outros, eram exemplos de como isso ocorria. "É importante ter presente que, além dos momentos repetidos durante todos os dias pela rotina, as demais atividades desenvolvidas no jardim-de-infância apresentavam também um modo ritualístico de desenvolvimento" (KUHLMANN JÚNIOR, 1998, p. 130).

Essa ritualização dos gestos corporais era uma tentativa de controlar as crianças o máximo de tempo possível. E mesmo quando as atividades sugeriam o movimento do corpo, como as aulas de ginástica, por exemplo, os movimentos geralmente eram padronizados e mecânicos, restando, talvez às crianças, o momento do recreio... Ou pelo menos deveria restar. Analisando o "Regimento Interno das Escolas Públicas de São Paulo", de 1891, vemos que nem sempre as crianças poderiam ter direito a esse momento.

No Capítulo IV do referido regimento, que tratava da disciplina escolar, nos Artigos 24 e 25 , eram previstos a aplicação de prêmios (como elogios perante a classe, distribuição de cartões de boas notas, local distinto de assento especial na sala, inclusão do nome do aluno do quadro de honra), da forma como bem parecer aos professores aplicar. Já entre os castigos, eram previstos algumas penas que poderiam variar conforme o arbítrio dos professores e a gravidade do ato ocorrido, entre eles, na letra "d" do Artigo 27 a "privação do recreio, ficando os alumnos punidos sob a vigilância do adjuncto ou do professor na própria sala ou no recreio" (SÃO PAULO, 1891, p.21). Em parágrafo único do referido Artigo havia, entretanto, uma cláusula de "consolo": "§ único. A privação do recreio escolar não deve ser completa, será determinada de modo que o alumno tenha pelo menos 5 minutos de inteira liberdade”. (SÃO PAULO, 1891, p. 21).

A privação do recreio é algo que acontece até os dias atuais. Apesar de haver muitos discursos de que não podemos privar as crianças desse momento, pois elas têm direito a esse tempo, essa é uma prática que ainda resiste nos contextos escolares de hoje. 
Além da privação do recreio prevista pelo regimento, outras formas de controle também são possíveis de ser observada no regimento paulista de 1891. No Capítulo III, artigo 15, vemos que o controle do adulto era uma constante dentro da sala de aula a tal ponto que as mobílias da época teriam que ser feitas de modo a facilitar a vigilância:

Artigo 15: A mobília escolar contará da que for determinada pelo Conselho Superior, devendo sua construção ter por base modelos que mais facilitem a vigilância do professor, a responsabilidade individual do alumno e a satisfação dos preceitos hygiênicos. (SÃO PAULO, 1891, p.7).

Não é possível hoje inferir se as normas atuais relacionadas à construção dos móveis escolares seguem norma parecida - objetivando a eficaz vigilância do professor (nem é nosso objetivo averiguar a existência de tal) dentro das salas de aulas -, mas é fato que essa fiscalização realizada pelo professor ou outros adultos que trabalham no ambiente escolar ocorre hoje de várias formas.

O que pretendemos, então, com essa discussão sobre a disciplinarização dos corpos, sobretudo por meio dos corpos infantis nos contextos escolares, é nos permitir a seguinte reflexão: por que, há mais de um século, tentamos moldar nossas crianças pela escola e por meio do corpo? Por que, até os dias atuais, percebemos uma privação do movimento, do jogo, da brincadeira, e outras significações que nos remetem ao "sujeito lúdico" nos contextos escolares? Por que a escola não se permitiu evoluir no sentido de enxergar o lúdico como um importante aliado dentro das escolas - pelo contrário, ainda pensamos na imposição de padrões de conduta através dos corpos das crianças?

A escola, infelizmente, parou no tempo, como diria Freire (2006). Entendemos que os muitos problemas educacionais, que não vem ao caso mencioná-los aqui de tão infinitos que são, ainda acontecem porque a escola não mudou, enquanto que muitos setores de nossa sociedade, as pessoas, os meios de comunicação, o mundo inteiro se transformou. Se as pessoas mudaram, se nossos alunos são muito diferentes do tempo em que nós mesmos estudávamos, se nossas crianças não são mais as mesmas, a escola, que é uma das instituições que mais está ligada à formação científica, técnica e humana das pessoas no início de suas vidas, também deveria ter buscado essa transformação.

Acreditamos que essa explanação histórica nos transporta a uma reflexão: hoje, o que ocorre em muitas instituições escolares, são frutos de escolhas feitas no passado. Não nos cabe, nesse momento, julgar se tais decisões foram as mais acertadas ou não, se os motivos reais eram bons ou maus. Importa é pensarmos: até quando reagiremos, na escola presente, com pensamentos pautados no século passado? A criança de hoje é uma criança moderna, globalizada, com necessidades virtuais típicas, que buscam romper fronteiras culturais e sociais pelas tecnologias. É o que Feicha (2011) denomina de "geração @", a primeira geração globalizada do século XXI - isso sem mencionarmos as gerações "x", "y", "z"... Estamos com crianças online para o mundo, enquanto a escola continua off-line em muitos assuntos - as práticas lúdicas dentro do contexto escolar é um deles.

\section{Considerações finais}

Vimos que foram muitas as formas encontradas para a disciplinarização do corpo infantil no contexto escolar brasileiro. Entende-se como "corpo disciplinado" aquele corpo imóvel, quieto, em silêncio que, na concepção atual de muitos, é um corpo que aprende mais e melhor.

Independente do motivo para que essa visão ainda se perpetue em nossas escolas em muitos momentos, seja de ordem histórica, por comodismo, pela formação deficitária, pela falta de tempo, pelo fato de haver pouco espaço no currículo para as práticas lúdicas, pelo pouco investimento financeiro, pelo mínimo de reconhecimento do jogo e da brincadeira como importantes, pela ausência 
de políticas públicas que reconheçam as especificidades da ludicidade, etc., precisamos refletir e mudar algumas de nossas concepções pedagógicas a respeito dessa temática na Educação.

O furto do lúdico nos contextos escolares do Brasil é algo que se arrasta desde o início de seu processo de escolarização e ainda hoje é comum presenciarmos em algumas escolas, por exemplo, os castigos por meio da subtração dos recreios para as crianças que "não se comportam muito bem" uma ação que se iniciou na rotina das escolas públicas há muito tempo.

Dizemos "ainda hoje", pois vemos que muitos de nossos costumes, hábitos, regras e conceitos adotados atualmente como disciplinarização no contexto escolar são originados historicamente há mais de um século. Muitos modelos antigos de punições às crianças por meio de imposições de imobilidade no período em que estão nas escolas ainda ocorrem com muita frequência. Considerando as rápidas mudanças de nossa sociedade, especialmente as ocorridas no século XX como a globalização, o avanço tecnológico, a agilidade das informações que foi surpreendentemente difundida pela Internet, os valores sociais e culturais, entre tantos outros, podemos afirmar com convicção que a escola pública brasileira, literalmente, parou no tempo.

Afirmamos isso, pois não é possível uma educação incentivar nossas crianças a serem curiosas pelos conhecimentos científicos, se ela poda as culturas infantis em muitos momentos pelo cerceamento do movimento, pelo impedimento de demonstrar suas opiniões, pela negação de sua fala, pela proibição do lúdico. A maioria das escolas hoje parece trabalhar contra as experiências lúdicas que as crianças podem ter com seus pares nesse ambiente, ainda com a forte e velha argumentação de que o jogo e a brincadeira descontrolam nossas crianças, as deixam indisciplinadas, além de as práticas lúdicas estarem diretamente ligadas a áreas menos importantes para alguns professores, pois os conteúdos "importantes" são aqueles que "fazem pensar", e para pensar é preciso silêncio, que precisa de atenção, que exige imobilidade e obediência. Uma verdadeira reação em cadeia!

O fato, é que infelizmente ainda hoje presenciamos muito o furto do lúdico nas escolas. As crianças inseridas atualmente em nosso sistema educacional estão a todo instante nos revelando como são rigorosas as privações do jogo e da brincadeira nesse contexto e, ainda, com relação às reflexões sobre os possíveis motivos nos quais essas proibições continuam ocorrer no contexto escolar, pensamos ter, por meio deste trabalho, refletido sobre alguns deles. O principal, sem dúvida, foi estabelecer um elo entre o passado, nossa história educacional, e os vários contextos sociais e políticos que contribuíram para o que ainda hoje chamamos de disciplinarização do corpo infantil em muitas escolas.

Não podemos, entretanto, deixar de inferir também que, independente da época, do contexto, da política vigente e da proibição das manifestações lúdicas infantis pelos adultos, ao longo da história, as crianças sempre encontram um meio de continuar sendo crianças, manifestados por meio de práticas lúdicas que não podemos interferir, como o caso "fíctício" da "menina que aprendeu a voar" ("fictício" entre aspas, pois sabemos que apesar de se tratar de uma história inventada, como frisada no início desse artigo, acontece com muita frequência em várias instituições escolares) e que serviu de ilustração para iniciarmos nossa discussão sobre a realidade de muitas escolas hoje.

Saindo da ficção para a vida real, as crianças de muitos contextos escolares desafiam o que já está muitas vezes preestabelecido pelos adultos. Podemos, muitas vezes, tentar abolir o lúdico, mas não conseguiremos, pois ele sempre existirá nos sonhos e comporá a vida da maioria das crianças.

Lúcia começou a olhar pela janela e as nuvens passavam, tão brancas, e o céu era tão azul, e em algum lugar do mundo as ondas do mar batiam na praia e levantavam espuma, e no parque tinha roda-gigante e montanha-russa. 
E na esquina tinha o pipoqueiro e o homem que vendia algodão-doce e tinha um gordo que vinha pela rua assobiando uma música tão bonita e Lúcia se distraiu e soltou os pés da carteira e começou a subir, a subir... E quando Lúcia olhou, viu que a Tábata também estava voando, e o Zé Bento também, e o Cassiano, a Denise, o Davi, o Pedro, a Juliana... (...) Tinha crianças gordas e magras, altas e pequeninas, louras, mulatas e morenas, tinha crianças inteligentes e burras, e voavam todas, rindo-se muito, alegres pelo céu.

Só uma ou outra criança não conseguiu voar e ficou tristinha, sentada na classe.

Dona Isolda chegou à janela, olhou para o alto e chorou uma lágrima salgada (Ruth Rocha - A menina que aprendeu a voar).

Independente de permitirmos ou não, de proibirmos ou não, as crianças continuarão a brincar nem que seja em um local em que nós, os adultos, muitas vezes não podemos entrar a não ser que as próprias crianças nos convidem: dentro da cabecinha delas, pela imaginação, em seus sonhos... Que tal nos lembrarmos de nossa velha infância e participar junto com elas desse momento? Ainda podemos transformar o percurso histórico que ainda está por vir.

\section{Referências}

AGAMBEN, G. Infância e história. Destruição da experiência e origem da história. Belo Horizonte: Editora UFMG, 2014, 186 p.

ALTMAN, R.Z. Brincando na história. In: DEL PRIORE, M. (Org.). História das crianças no Brasil. São Paulo: Contexto, 2010, p. $231-258$.

ARIÈS, P. História social da criança e da família. Rio de Janeiro: Zahar, 1978, 279 p.

BINZER, I. V. Os meus romanos. Alegrias e tristezas de uma educadora alemã no Brasil. Tradução: ROSSI, A.; CERQUEIRA, L. G. Rio de Janeiro: Paz e Terra, 2011, 171 p.

CARVALHO, M.M. C. Quando a história da educação é a história da disciplina e da higienização das pessoas. In: FREITAS, M. C. (Org.). História Social da Infância no Brasil. São Paulo: Cortez, 1997, p. 291 - 309.

CHAMBOULEYRON, R. Jesuítas e as crianças no Brasil quinhentista. In: DEL PRIORE, M. (Org.). História das crianças no Brasil. São Paulo: Contexto, 2010, p. 49 - 74.

DEL PRIORE, M. História das crianças no Brasil. Apresentação. In: DEL PRIORE, M. (Org.). História das crianças no Brasil. São Paulo: Contexto, 2010, p. 6 - 18.

DEL PRIORE, M. O cotidiano da criança livre no Brasil entre a colônia e o império. In: DEL PRIORE, M. (Org.). História das crianças no Brasil. São Paulo: Contexto, 2010, p. 74 - 95.

ERIKSON, E. H. Infância e Sociedade. Rio de Janeiro: Zahar, [S/D], 404 p.

FEIXA, C. Tarzan, Peter Pan, Blade Runner: relatos juvenis na era global. In: PAIS, J. M.; BENDIT, R.; FERREIRA, V. S. (Orgs). Jovens e rumos. Imprensa de ciências sociais. Lisboa, 2011, p. $203-222$.

FOUCAULT, M. Vigiar e Punir. História das violências nas prisões. Petrópolis: Vozes, 1987, 280p. 
FREIRE, J. B. Uma pedagogia lúdica. In: ARANTES, V. A. (Org.). Humor e alegria na educação. São Paulo: Summus, 2006, p. 127 - 149.

GAGNEBIN, J. M. História e narração em Walter Benjamin. São Paulo: Perspectiva, 2013, 114p.

GOIS JÚNIOR, E.; BATISTA, J. C. F. A introdução da gymnastica na escola normal de São Paulo (1890 - 1908). Movimento, Porto Alegre, v.16, n.3, p.71-87, Jul./Set. 2010. https://doi.org/10.22456/1982-8918.11491

GOMES-DA-SILVA, P. N. Cultura corporal burguesa. História e sistematizações pedagógicas. João Pessoa: Editora Universitária da UFPB, 2012, 347p.

KOHAN, W. O. Infância. Entre educação e filosofia. Belo Horizonte: Autêntica, 2003, 263p.

KUHKMANN JR., M. Relações sociais, intelectuais e educação da infância na história. In: SOUZA, G. Educar na infância: perspectivas histórico-sociais. São Paulo: Contexto, 2010, p.81-97.

KUHLMANN JR., M. Infância e educação infantil. Uma abordagem histórica. Porto Alegre: Mediação, 1998, 210p.

LEITE, M. L. M. A infância no século XIX segundo memórias e livros de viagem. In: FREITAS, M. C. (Org.). História Social da infância no Brasil. São Paulo: Cortez, 1997, p.19-52.

MARCILIO, M. L. De criança a escolar. In: SOUZA, G. Educar na infância: perspectivas histórico-sociais. São Paulo: Contexto, 2010, p.41-65.

MONARCHA, C. Arquitetura escolar republicana: a escola normal da praça e a construção de uma imagem de criança. In: FREITAS, M. C. (Org.). História Social da Infância no Brasil. São Paulo: Cortez, 1997, p.101-140.

MOURA, E. B. B. Crianças operárias na recém-industrializada São Paulo. In: DEL PRIORE, M. (Org.). História das crianças no Brasil. São Paulo: Contexto, 2010, p. 259 - 288.

RIBEIRO, R. J. O poder de infantilizar. In: GHIRALDELLI JÚNIOR, P. (Org.). Infância, escola e modernidade. Curitiba, Cortez, 1997, p.101-109.

RIZZINNI, I. O século perdido. Raízes históricas das políticas públicas para a infância no Brasil. São Paulo: Cortez, 2011, 199p.

ROCHA, R. A menina que aprendeu a voar. São Paulo: Moderna, 2012, 32p.

ROMANELLI, O. O. História da Educação no Brasil. 36ª ed. Petrópolis: Vozes, 2010, 279p.

SANTANA, D. R. Infância e Educação Infantil no Brasil: percursos e percalços. Enciclopédia Biosfera, Goiânia, v.7, n.12, p.1-12, 2011.

SÃO PAULO. Regimento interno das escolas públicas do Estado de São Paulo. Decreto $n^{\circ} 248$ de 26 de julho de 1894. Aprova o regimento interno das escolas publicas. São Paulo, 1891.

VEIGA, C. G. As crianças na história da educação. In: SOUZA, G. Educar na infância: perspectivas histórico-sociais. São Paulo: Contexto, 2010, p.21-39. 